\title{
Produção de biomassa, de açúcar e de proteína em função de variedades de cana e de adubação fosfatada
}

\section{Production of biomass, from sugar and protein in function of sugarcane varieties and phosphorous fertilization}

\author{
Altanys Silva Calheiros ${ }^{1 *}$; Mauro Wagner de Oliveira²; \\ Vilma Marques Ferreira ${ }^{3}$; Geraldo Veríssimo de Souza Barbosa ${ }^{4}$; \\ Antônio Dias Santiago ${ }^{5}$; Edna Vieira dos Santos Aristides ${ }^{6}$
}

\begin{abstract}
Resumo
A cana-de-açúcar é uma forragem que apresenta limitações nutricionais, devido aos baixos teores de proteína, de fósforo e de enxofre, entretanto, a adubação fosfatada pode melhorar sua qualidade nutricional, pois influencia na absorção e no metabolismo do nitrogênio e do fósforo. No presente estudo, avaliaram-se, no ciclo de cana-planta, o acúmulo de matéria seca, de fósforo e de proteína bruta e a produção de sacarose de duas variedades de cana-de-açúcar em função da adubação fosfatada. O estudo foi um fatorial 2 x 6, constituído de duas variedades de cana, RB867515 e RB92579, e seis doses de fósforo: zero, 30, 60, 90, 120 e $150 \mathrm{~kg} \mathrm{ha}^{-1} \mathrm{de} \mathrm{P}$, com os tratamentos distribuídos em blocos ao acaso, com cinco repetições. Utilizou-se também adubação nitrogenada e potássica em doses equivalentes a 100 e $200 \mathrm{~kg} \mathrm{ha}^{-1}$ de $\mathrm{N}$ e K, respectivamente. A adubação fosfatada influenciou no acúmulo de matéria seca e de sacarose, havendo efeito quadrático. Houve efeito linear, mas discreto, das doses de P sobre a concentração desse elemento na matéria seca, o que não foi observado para a concentração de proteína bruta. Por outro lado, os acúmulos de proteína e de fósforo foram significativamente influenciados pela adubação.
\end{abstract}

Palavras-chave: Alimentação animal, nutrição mineral, produtividade, qualidade da forragem

\begin{abstract}
The sugarcane is a fodder that presents nutritional limitations, due to low levels of protein, phosphorus and sulfur; however, the phosphorous fertilization can improve its nutritional quality, because it influences in the absorption and the metabolism of nitrogen and phosphorus. In this study, the accumulation of dry substance from phosphorus and raw protein and the production of sucrose from two sugarcane varieties in function of the phosphorous fertilization in the sugarcane - plant cycle were evaluated. The study was a 2 × 6 factorial, consisted of two sugarcane varieties, RB867515 and RB92579, and six doses of phosphorus: zero, 30, 60, 90, 120 and $150 \mathrm{~kg} \mathrm{ha}^{-1}$ of $\mathrm{P}$, with treatments distributed in blocks at random, with five repetitions. Nitrogen and potassium fertilization in doses equivalent to 100 and $200 \mathrm{~kg} \mathrm{ha}^{-1}$ of $\mathrm{N}$ and $\mathrm{K}$ were also used respectively. The phosphorous fertilization influenced in the accumulation
\end{abstract}

${ }^{1}$ Doutorando da Universidade Federal Rural de Pernambuco, UFRPE, Recife, PE. E-mail: altanys.asc@gmail.com

${ }^{2}$ Prof. Adjunto, Setor de Agricultura, Universidade Federal de Alagoas, UFAL, CEP: 57100-000, Maceió, AL. E-mail: maurowoliveira@gmail.com

${ }^{3}$ Prof $^{\mathrm{a}}$ Adjunta, Dept ${ }^{\mathrm{o}}$ de Fisiologia Vegetal, UFAL, Maceió, AL. E-mail: vmarques ferreira@hotmail.com

${ }^{4}$ Prof. Adjunto, Dept ${ }^{\mathrm{o}}$ de Agronomia, UFAL, Maceió, AL. E-mail: gvsbarbosa@gmail.com

${ }_{5}^{5}$ Pesquisador, Embrapa Tabuleiros Costeiros. Rio Largo, AL. E-mail: santiago@cpatc.embrapa.br

${ }^{6}$ Zootecnista, TIMAC Agro: Indústria e Comércio de Fertilizantes Ltda, Santa Luzia do Norte, Alagoas. E-mail: ednaaristides@, gmail.com

* Autor para correspondência 
of dry substance and sucrose, having a quadratic effect. There was a linear effect, but discrete, of the doses of $\mathrm{P}$ on the concentration of this element in the dry substance, which was not observed for the raw protein concentration. On the other hand, the protein and phosphorus mass were significantly influenced by the fertilization.

Key words: Animal feeding, mineral nutrition, productivity, quality of the fodder

\section{Introdução}

A cana-de-açúcar tem sido um volumoso muito utilizado para alimentação animal e, dentre os principais fatores que contribuem para o seu uso no arraçoamento animal, podem-se citar: 1) A grande produção de forragem por unidade de área e a facilidade de cultivo - quando está madura, mantém sua qualidade como forragem, além do baixo custo por unidade de matéria seca produzida; 2) Apresenta maior flexibilidade quanto às épocas de plantio e de corte, em comparação com as culturas anuais, o que facilita o gerenciamento da atividade; e 3) Pode ser uma das fontes de energia de menor custo, tanto para rebanhos de pequena quanto de média e alta produtividade, tornando essa forrageira um alimento de grande interesse dos produtores (FREITAS et al., 2006a; 2006b; BAILEIRO NETO et al., 2007; OLIVEIRA et al., 2007).

Essa forrageira, por produzir grande quantidade de biomassa, extrai e acumula, conseqüentemente, maior quantidade de nutrientes do solo. Para uma produção de 120 toneladas de matéria natural por hectare, cerca de $100 \mathrm{t}$ de colmos industrializáveis, o acúmulo de nutrientes na parte aérea da planta é da ordem de 150, 40, 180, 90, 50 e $40 \mathrm{~kg}$ de $\mathrm{N}$, $\mathrm{P}, \mathrm{K}, \mathrm{Ca}, \mathrm{Mg}$ e $\mathrm{S}$, respectivamente. No caso dos micronutrientes $\mathrm{Fe}, \mathrm{Mn}, \mathrm{Zn}, \mathrm{Cu}$ e $\mathrm{B}$, os acúmulos na biomassa da parte aérea, também para uma produção de 120 t, são por volta de 8,$0 ; 3,0 ; 0,6 ; 0,4$; e $0,3 \mathrm{~kg}$, respectivamente (OLIVEIRA et al., 2007).

O fósforo juntamente com o nitrogênio são os elementos que de modo geral mais limitam o crescimento da cana. A disponibilidade endógena de fósforo, principalmente a quantidade de ATP no sistema radicular, controla a absorção, a translocação e o metabolismo do nitrato (MACHADO et al., 2003; MENDES et al., 2004; OLIVEIRA et al, 2007; SILVA, 2007). Assim, a concentração de fósforo e de proteína na biomassa da cana-de-açúcar podem ser influenciadas pela adubação fosfatada.

No presente estudo, avaliaram-se, no ciclo de cana-planta, o acúmulo de biomassa, de fósforo e de proteína bruta e a produção de sacarose de duas novas variedades de cana-de-açúcar, RB867515 e RB92579, de alto potencial produtivo, em função da adubação fosfatada.

\section{Material e Métodos}

A pesquisa foi conduzida em área experimental do Centro de Ciências Agrárias da Universidade Federal de Alagoas, no Município de Rio Largo AL, situado na latitude de $9^{\circ} 29^{\prime} 45^{\prime}$ S, longitude de $35^{\circ} 49^{\prime}$ '54" W e altitude média de 127 metros. O solo da área experimental é um Latossolo Amarelo Coeso Distrófico, com relevo plano (EMBRAPA, 2006).

Antecedendo à instalação do experimento realizou-se análise química do solo na camada de 0 a $20 \mathrm{~cm}$, cujos resultados foram, respectivamente: pH em $\mathrm{H}_{2} \mathrm{O}: 5,6 ; \mathrm{Al}^{+3}, \mathrm{Ca}^{+2}, \mathrm{Mg}^{+2}: 0,41 ; 1,50$ e 1,10 $\mathrm{cmol}_{\mathrm{c}} \mathrm{dm}^{-3}$; P e K: 6,0 e $38 \mathrm{mg} \mathrm{dm}^{-3}$; CTC (T): 7,20 $\mathrm{cmol}_{\mathrm{c}} \mathrm{dm}^{-3}$ e V (\%): 37,4. De posse dos resultados, calculou-se a quantidade de calcário dolomítico a ser aplicada para se elevar a saturação por bases a $60 \%$. Após a aplicação do calcário, a área experimental foi arada, gradeada e sulcada, tendo-se realizado o plantio da cana em 09 de setembro de 2005.

O estudo foi um fatorial $2 \times 6$, constituído de duas variedades de cana; RB867515 e RB92579, e seis doses de fósforo: zero, 30, 60, 90, 120 e $150 \mathrm{~kg}$ $\mathrm{ha}^{-1} \mathrm{de} \mathrm{P}$, tendo como fonte de fósforo o superfosfato triplo. Utilizou-se também adubação nitrogenada e potássica em doses equivalentes a 100 e $200 \mathrm{~kg}$ $\mathrm{ha}^{-1}$ de $\mathrm{N}$ e $\mathrm{K}$, respectivamente. $\mathrm{O}$ delineamento 
experimental utilizado foi o de blocos ao acaso, com cinco repetições, sendo as parcelas constituídas de cinco sulcos de 10,0 metros de comprimento, espaçados de 1,20 metros.

Para evitar possíveis perdas de N por volatilização de amônia pela folhagem da cana durante o período seco, apenas um terço do $\mathrm{N}$, na forma de sulfato de amônio, juntamente com a totalidade do $\mathrm{K}$, tendo como fonte o $\mathrm{KCl}$, foram aplicados no fundo do sulco de plantio. No início das primeiras precipitações do período chuvoso de 2006 foi realizada a adubação nitrogenada em cobertura, na dose de $67 \mathrm{~kg} \mathrm{ha}^{-1}$ de $\mathrm{N}$ e com micronutrientes em doses equivalentes a 6,0 ; 6,0 e 7,0 $\mathrm{kg} \mathrm{ha}^{-1}$ de $\mathrm{Cu}, \mathrm{Mn}$ e $\mathrm{Zn}$, respectivamente, tendo-se como fontes de micronutrientes o sulfato de cobre, sulfato de manganês e sulfato de zinco. $\mathrm{O}$ controle químico de plantas daninhas foi feito utilizando-se herbicida pré-emergente alachor e atrazine.

Em dezembro de 2006 realizou-se a colheita da cana-planta, avaliando-se o acúmulo de nutrientes, de biomassa e sacarose na parte aérea da cana por meio de amostragens, sendo de $10,8 \mathrm{~m}^{2}$ a área de cada amostra. Após a determinação da matéria fresca, subamostras de toda a parte aérea de cada tratamento foi passada em picadeira de forragem e seca em estufa de ventilação forçada a $65^{\circ} \mathrm{C}$ até massa constante. Essas subamostras foram passadas em moinho tipo Willey com peneira de crivos de 1,0 $\mathrm{mm}$, sendo, posteriormente, quantificado os teores de proteína bruta e de fósforo segundo métodos descrito por Silva (1990) e Malavolta, Vitti e Oliveira (1989), respectivamente. Os valores médios do acúmulo de matéria seca, proteína bruta, fósforo e de sacarose (FERNANDES, 2000) foram extrapolados para um hectare e, submetidos à análise de variância e, de regressão para as variáveis estudadas, por meio do programa estatístico SISVAR (FERREIRA, 2008).

\section{Resultados e Discussão}

O acúmulo de matéria seca na parte aérea das plantas (Ac. MS) foi grandemente influenciado pela variedade e pelas doses de fósforo (Tabela 1). $\mathrm{O}$ valor médio do Ac. MS, para todas as doses de $\mathrm{P}$, foi de $30.734 \mathrm{~kg} \mathrm{ha}^{-1}$ para a RB867515 e de $35.253 \mathrm{~kg}$ ha $^{-1}$ para a RB92579 (Tabela 2 e Figura 1). Silveira et al. (2002), em trabalhos conduzidos na Zona da Mata Mineira, em solos com baixo teor de P e média saturação por bases, avaliaram o crescimento e a produção de sacarose por seis variedades de cana e verificaram que a RB867515 destacou-se pelo acúmulo de matéria seca e produção de sacarose, com médias de 56 e 16,6 t ha ${ }^{-1}$, respectivamente.

Em pesquisa conduzida por Rossiello (1987) com a variedadeNA56-79, na região norte fluminense, em solos com alto teor de fósforo e saturação por bases próxima a $55 \%$, verificou-se acúmulos de matéria seca da ordem de $47 \mathrm{t} \mathrm{ha}^{-1}$, portanto, superiores aos do presente estudo. Porém, resultados semelhantes ao deste trabalho foram observados por Carvalho et al. (1993) ao avaliar o potencial produtivo das variedades CB47-355, SP70-1143, SP71-1406, RB72454 e NA56-79, uma vez que os acúmulos de biomassa seca na parte aérea das plantas variaram de 30,47 a $36,35 \mathrm{t} \mathrm{ha}^{-1}$.

Em Alagoas, a fase de máximo crescimento da cana-de-açúcar ocorre em dias curtos e, portanto sob baixa luminosidade, diferentemente do CentroSul do Brasil, onde o aumento da luminosidade coincide com a maior disponibilidade hídrica. A não coincidência da máxima disponibilidade hídrica com a luminosa influencia negativamente nas taxas fotossintéticas, resultando em menor produtividade da cana em Alagoas, quando comparada ao CentroSul.

Não houve efeito da adubação fosfatada e da variedade sobre a concentração de proteína bruta na matéria seca da parte aérea da cana-de-açúcar (Tabela 2) tendo-se obtido valor médio de $3,12 \mathrm{dag} \mathrm{kg}^{-1}$. O efeito da adubação sobre o acúmulo de proteína bruta deveu-se ao aumento da matéria seca em função da adubação fosfatada (Tabela 1 e Figura 2). 
Tabela 1. Quadrados médios da análise de variância para acúmulo de matéria seca (Ac. MS), teores (Teor) e acúmulos (Ac.) de proteína bruta e de fósforo na parte aérea das plantas e produção de colmos industrializáveis (Prod. Colmos) e de sacarose aparente (Sacarose), por duas variedades de cana adubadas com seis doses de fósforo.

\begin{tabular}{|c|c|c|c|c|c|c|c|c|}
\hline \multirow[b]{2}{*}{$\begin{array}{l}\text { Fonte de } \\
\text { variação }\end{array}$} & \multirow[b]{2}{*}{ GL } & \multicolumn{7}{|c|}{ 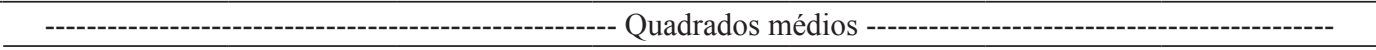 } \\
\hline & & Ac. MS. & Teor PB & Ac. PB & Teor Fósforo & Ac. Fósforo & Prod. Colmos & Sacarose \\
\hline Bloco & 4 & $6.803 .898,23^{\mathrm{ns}}$ & $0,1731^{\mathrm{ns}}$ & $36.497,96^{* *}$ & $0,0122^{\mathrm{ns}}$ & $6,6944^{\mathrm{ns}}$ & $183,79^{\text {ns }}$ & $1.139 .196,77^{\mathrm{ns}}$ \\
\hline Variedade $(\mathrm{V})$ & 1 & $306.343 .010,42^{* * *}$ & $0,0054^{\mathrm{ns}}$ & $308.596,82^{* * *}$ & $0,2788^{* * *}$ & $12,5858^{\mathrm{ns}}$ & $4.679,19^{* * *}$ & $67.130 .103,75^{* * *}$ \\
\hline Dose de P $(\mathrm{P})$ & 5 & $42.835 .014,94^{* * *}$ & $0,0785^{\mathrm{ns}}$ & $71.761,63^{* * *}$ & $0,0630^{* * * *}$ & $51,3044^{* * *}$ & $1.262,99^{* * *}$ & $10.664 .070,54^{* *}$ \\
\hline V x P & 5 & $673.866,06^{\mathrm{ns}}$ & $0,2807^{* *}$ & $30.485,98^{* *}$ & $0,0058^{\mathrm{ns}}$ & $3,4320^{\mathrm{ns}}$ & $197,75^{\mathrm{ns}}$ & $2.879 .295,23^{\mathrm{ns}}$ \\
\hline Resíduo & 44 & $6.235 .155,86$ & 0,0689 & $8.673,60$ & 0,0081 & 9,1952 & 118,93 & $2.181 .015,67$ \\
\hline CV (\%) & & 7,57 & 8,42 & 9,08 & 11,71 & 12,07 & 11,07 & 11,76 \\
\hline
\end{tabular}

ns, **** $\mathrm{e}^{* * *}=$ não significativo e significativo a 5,1 e $0,1 \%$ de probabilidade, pelo teste $\mathrm{F}$, respectivamente.

Fonte: Elaboração dos autores.

Tabela 2. Médias do acúmulo de matéria seca (Ac. MS), dos teores (Teor) e acúmulos (Ac.) de proteína bruta e de fósforo na parte aérea das plantas e produção de colmos industrializáveis (Prod. Colmos) e de sacarose aparente (Sacarose), por duas variedades de cana adubadas com seis doses de fósforo.

\begin{tabular}{|c|c|c|c|c|c|c|c|}
\hline \multirow[t]{2}{*}{ Variedades } & Ac. MS & Teor PB & Ac. PB & Teor Fósforo & Ac. Fósforo & Prod. Colmos & Sacarose \\
\hline & $\mathrm{kg} \mathrm{ha}^{-1}$ & dag $\mathrm{kg}^{-1}$ & $\mathrm{~kg} \mathrm{ha}^{-1}$ & dag $\mathrm{kg}^{-1}$ & \multicolumn{3}{|c|}{ 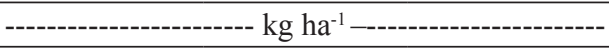 } \\
\hline RB867515 & $30.734 \mathrm{a}^{1}$ & $3,11 \mathrm{a}$ & $954 \mathrm{a}$ & $0,083 b$ & $25,58 \mathrm{a}$ & $89.646 \mathrm{a}$ & $11.496 \mathrm{a}$ \\
\hline RB92579 & $35.253 \mathrm{~b}$ & $3,13 \mathrm{a}$ & $1.097 \mathrm{~b}$ & $0,070 \mathrm{a}$ & $24,66 \mathrm{a}$ & $107.308 \mathrm{~b}$ & $13.612 b$ \\
\hline Médias & 33.313 & 3,12 & 1.025 & 0,076 & 25,12 & 98.477 & 12.524 \\
\hline
\end{tabular}

${ }^{1}$ Médias seguidas de mesma letra na coluna não diferem entre si, a $5 \%$ de probabilidade, pelo teste $\mathrm{F}$.

Fonte: Elaboração dos autores.

Figura 1. Acúmulo de matéria seca na parte aérea das variedades de cana-de-açúcar RB867515 e RB92579 em função de doses de fósforo.

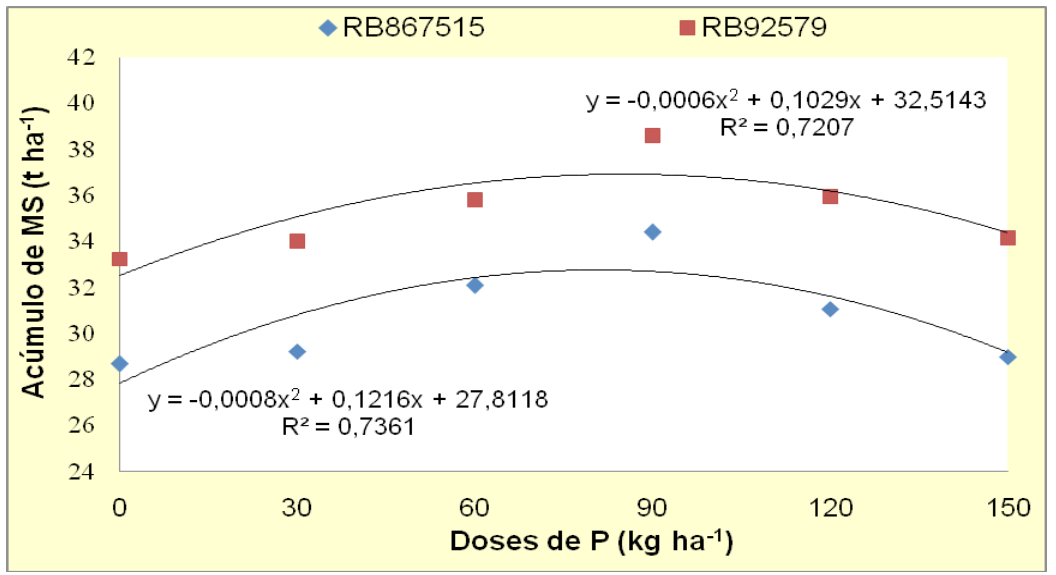

Fonte: Elaboração dos autores. 
Figura 2. Acúmulo de proteína bruta na parte aérea das variedades de cana-de-açúcar RB867515 e RB92579 em função de doses de fósforo.

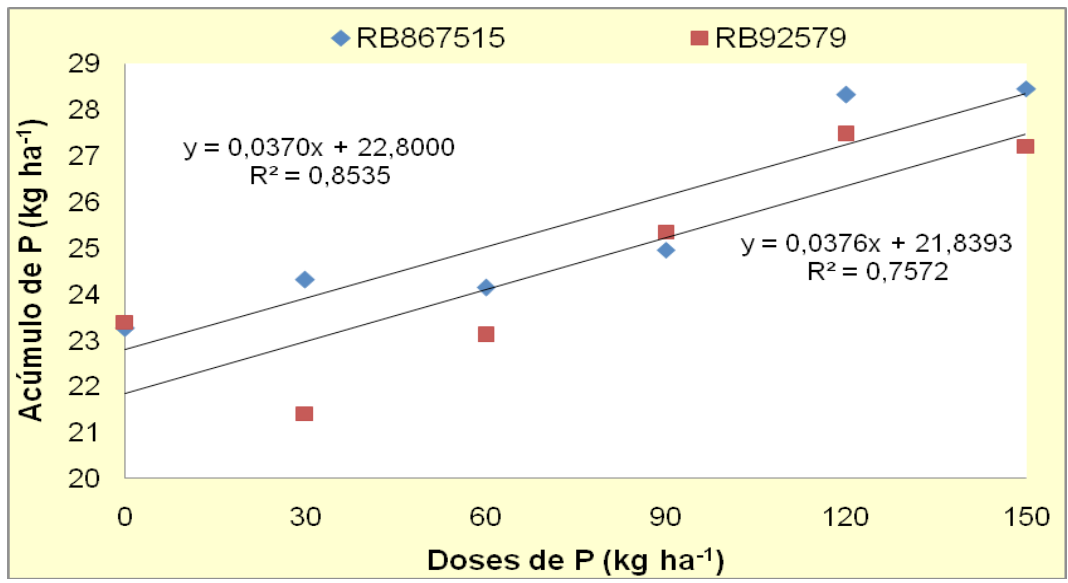

Fonte: Elaboração dos autores.

O teor de fósforo disponível na camada de 0 a $20 \mathrm{~cm}$ de profundidade, extraído com Mehlich foi de $6,0 \mathrm{mg} \mathrm{dm}^{-3}$, inferior aos $9,0 \mathrm{mg} \mathrm{dm}^{-3}$ definido como nível crítico por Albuquerque e Marinho (1982) para o Estado de Alagoas. Por isto, esperavase que houvesse efeito das doses de adubação fosfatada na concentração e acúmulo de proteína bruta na biomassa da parte aérea da cana-de-açúcar, pois há relatos de três efeitos distintos do aumento da disponibilidade endógena de $\mathrm{P}$ na absorção e no metabolismo do nitrato (MAGALHÃES, 1996; OLIVEIRA et al., 2007). Primeiramente, a absorção de nitrato pelas raízes aumenta, posteriormente, a translocação do nitrato das raízes para a parte aérea também aumenta, aparentemente devido à menor restrição do transporte do simplasto para o xilema. E, por último, há elevação no teor de aminoácidos, tanto nas folhas como nas raízes.

Os valores médios de proteína bruta obtidos no presente estudo são insuficientes para assegurar bom funcionamento do rúmen. Para dietas exclusivas de cana-de-açúcar, o teor de proteína bruta deveria situar-se entre 6,0 a 7,0 dag $\mathrm{kg}^{-1}$ (LIMA; MATTOS, 1993), entretanto em vários trabalhos conduzidos por diversos pesquisadores brasileiros têm-se verificado ampla variação no teor de proteína bruta da biomassa da parte aérea da cana-de-açúcar, com valores oscilando de 2,0 a 4,3 dag $\mathrm{kg}^{-1}$ (FRANZOLIN; LUCCI; FRANZOLIN, 2000; FERNANDES et al., 2001; BARBOSA et al., 2002; COLETI et al., 2002; MENDES, 2006; FERREIRA et al., 2007). Silva et al. (2007), apresentam resultados de avaliações bromatológicas realizadas por 20 autores, em quatorze variedades de cana atualmente cultivadas e, citam que os teores máximos de proteína foram de $3,37 \mathrm{dag}^{-1}$.

Outra possível alternativa para elevar o teor protéico da cana seria a adubação nitrogenada, entretanto, Salas et al. (1992) em estudo de adubação com doses de zero, 80, 150 e $300 \mathrm{~kg}$ de N por hectare por ano, verificaram que a fertilização provocou alterações muito pequenas no valor nutricional, havendo por outro lado grande influência da idade da cana sobre o teor protéico. O teor máximo de proteína; 3,37 dag $\mathrm{kg}^{-1}$ foi observado aos seis meses de idade da cana, coincidindo com as citações de Lima e Mattos (1993).

No presente estudo, observou-se efeito de doses de adubação fosfatada e de variedades sobre a concentração de fósforo na biomassa da parte aérea da cana-de-açúcar (Tabela 1). O efeito da adubação sobre a concentração do fósforo na parte aérea da cana-de-açúcar foi linear e muito discreto, embora significativo $(\mathrm{P}<0,001)$, tendo-se obtido a equação 
$\mathrm{y}=0,00007 \mathrm{x}+0,0708826$. Verificou-se também que a concentração de $\mathrm{P}$ na biomassa da parte aérea da RB867515 foi cerca de 20\% maior que a da RB92579 (Tabela 2), com valores de 0,0838 e 0,0701 dag kg1, respectivamente. Korndorfer e Alcarde (1992), em estudo conduzido com a variedade SP71-1406 também verificaram efeito da adubação fosfatada sobre o teor de fósforo, entretanto o conteúdo máximo de P na biomassa seca foi de apenas 0,0362 dag $\mathrm{kg}^{-1}$. Segundo Lima e Mattos (1993) esse teor deveria ser no mínimo de $0,28 \mathrm{dag}_{\mathrm{kg}^{-1}}$ para atender as exigências de uma vaca em lactação produzindo $10 \mathrm{~kg}$ de leite por dia.

$\mathrm{O}$ baixo teor protéico associado às outras limitações nutricionais da cana, como alto teor de fibra de difícil degradação ruminal, baixos teores de amido, fósforo e enxofre, resultam em consumo e rendimento limitados, havendo, portanto, necessidade de complementação com proteína, minerais e amido para que a produtividade animal seja satisfatória (LIMA; MATTOS, 1993, ANDRADE et al., 2001; FERNANDES et al., 2001).

Não se constatou efeito varietal no acúmulo de fósforo na biomassa da parte aérea da cana-deaçúcar (Tabelas 1 e 2 e Figura 3), sendo o acúmulo médio de $25,12 \mathrm{~kg} \mathrm{ha}^{-1}$ de $\mathrm{P}$, próximos aos relatados por Coleti et al. (2002), mas cerca da metade do acúmulo verificado na RB72454, por Barbosa et al. (2002), na Zona da Mata Mineira. Em pesquisa conduzida por Mendes (2006) com oito variedades de cana-de-açúcar também se observou que a RB867515 juntamente com a SP803280 foram as que mais acumularam $\mathrm{P}$, com valores da ordem de $42 \mathrm{~kg} \mathrm{ha}{ }^{-1}$, contudo a diferença entre o maior e o menor acúmulo foi de apenas $11 \%$.

Figura 3. Acúmulo de P na parte aérea das variedades de cana-de-açúcar RB867515 e RB92579 em função de doses de fósforo.

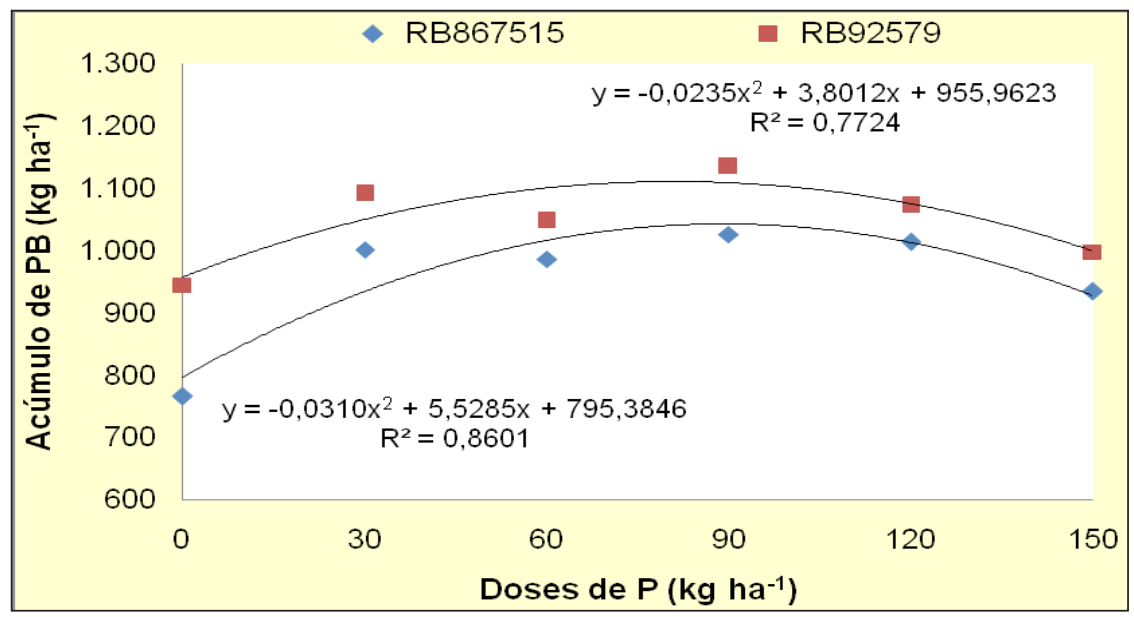

Fonte: Elaboração dos autores.

A produção de colmos industrializáveis apresentou diferenças significativas para as variedades e doses de P (Tabelas 1 e 2 e Figura 4). Obtiveram-se equações de regressão do efeito da adubação fosfatada sobre a produção de colmos industrializáveis para as variedades RB867515 e
RB92579 de: $y=-0,0026 x^{2}+0,4372 x+77,6820$ $\left(R^{2}=0,7141\right)$ e $y=-0,0055 x^{2}+0,8438 x+89,3981$ $\left(\mathrm{R}^{2}=0,8101\right)$, respectivamente. As doses de fósforo que propiciaram a maior produção de colmos foram de 84,1 e $76,7 \mathrm{~kg} \mathrm{ha}^{-1}$ de $\mathrm{P}$, respectivamente para a RB867515 e RB92579. Cavalcante (1978) conduziu 
estudos em Goiana - PE, com a variedade CB54-3, em solos apresentando teor de fósforo de $7,0 \mathrm{mg} \mathrm{kg}^{-}$ ${ }^{1}$, e verificou por meio do uso da lei de Mitscherlich que a dose ótima de $\mathrm{P}$ foi de 103,9 kg por hectare.

A resposta à adubação fosfatada é influenciada por fatores edafoclimáticos, hídricos e também pela capacidade da planta de absorver e utilizar esse nutriente na fixação do $\mathrm{CO}_{2}$ atmosférico e na produção de compostos orgânicos (CAVALCANTE, 1978; RAIJ, 1991; NOVAIS; SMITH, 1999; MACHADO et al., 2003; MENDES, 2006; OLIVEIRA et al., 2007).
O acúmulo médio de sacarose aparente na RB92579 alcançou $13.610 \mathrm{~kg} \mathrm{ha}^{-1}$, enquanto para a RB867515 este valor foi de $11.490 \mathrm{~kg} \mathrm{ha}^{-1}$ (Tabela 2). O acúmulo de sacarose aparente na RB867515 relatados por Mendes (2006), de cerca de $20 \mathrm{t} \mathrm{ha}^{-}$ 1, na Zona da Mata Mineira, foram superiores aos encontrados neste experimento, isto, certamente está relacionado com radiação solar, quantidade de luz interceptada e a disponibilidade de água ao longo do ciclo, tendo em vista que o teor de fósforo no solo era da ordem 4,0 $\mathrm{mg} \mathrm{dm}^{-3}$, entretanto o crescimento ocorreu sob noites curtas decrescente, diferindo das condições observadas em Alagoas, onde os verões são secos.

Figura 4. Produção de colmos industrializáveis e de sacarose pelas variedades de cana-de-açúcar RB867515 e RB92579 em função de doses de fósforo.
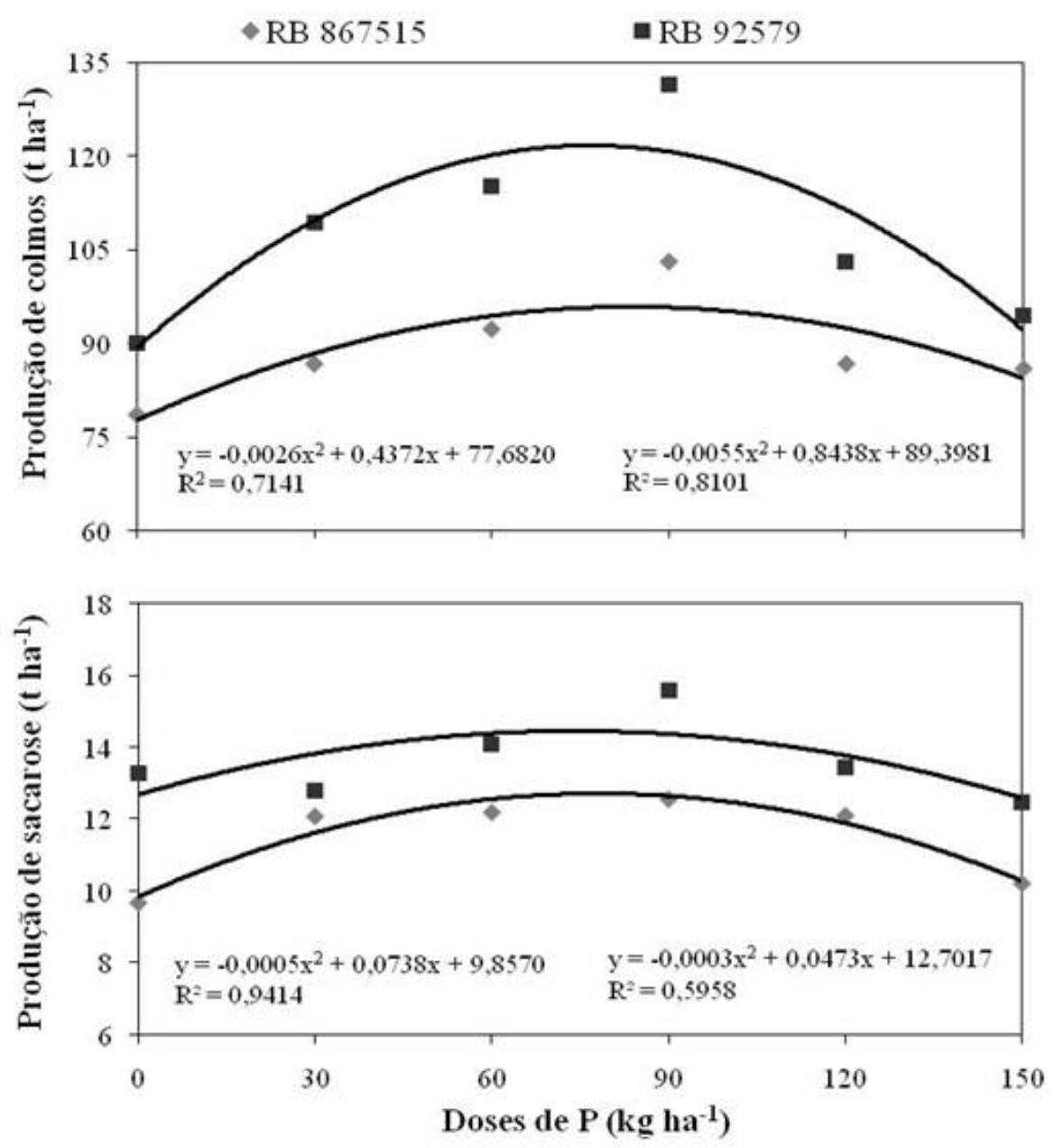

Fonte: Elaboração dos autores. 


\section{Conclusões}

Os acúmulos de matéria seca, de sacarose, de fósforo e de proteína bruta foram influenciados pela adubação fosfatada;

Não houve efeito da adubação fosfatada e da variedade sobre a concentração de proteína bruta na biomassa da parte aérea da cana-de-açúcar;

Observou-se efeito linear, mas discreto, da adubação sobre a concentração do fósforo na biomassa da parte aérea da cana-de-açúcar.

\section{Referências}

ALBUQUERQUE, G. A. C.; MARINHO, M. L. Efeitos do parcelamento e épocas de adubação da cana-de-açúcar em Alagoas. Brasil Açucareiro, Rio de Janeiro, v. 100, n. 2, p. 17-23, 1982.

ANDRADE, J. B.; FERRARI JUNIOR, E.; POSSENTI, R. A.; LEINZ, F. F.; BIANCHINI, D.; RODRIGUES, C. F. C. Valor nutritivo da cana-de-açúcar na forma de silagem ou "in natura". Boletim de Indústria Animal, Nova Odessa, v. 58, n. 2, p. 135-143, 2001.

BAILEIRO NETO, G.; SIQUEIRA, G. R.; REIS, R. A.; NOGUEIRA, J. R.; ROTH, M. T. P.; ROTH, A. P. T. P. Óxido de cálcio como aditivo na ensilagem de cana-deaçúcar. Revista Brasileira de Zootecnia, Viçosa, MG, v. 36, n. 5, p. 1231-1239, 2007.

BARBOSA, M. H. P.; OLIVEIRA, M. W.; SILVEIRA, L. C. I.; DAMASCENO, C. M.; MENDES, L. C. Acúmulo e alocação de nutrientes pela RB72454 no ciclo da cana-planta. In: CONGRESSO NACIONAL DA SOCIEDADE DOS TÉCNICOS AÇÚCAREIROS E ALCOOLEIROS DO BRASIL, 8., 2002. Recife. Anais... Recife: STAB, 2002. p. 264-267.

CARVALHO, G. J.; ANDRADE, L. A. B.; EVANGELISTA, A. R.; OLIVEIRA, P. S. R. Avaliação do potencial forrageiro de cinco variedades de canade-açúcar (ciclo de ano) em diferentes estádios de desenvolvimento. STAB - Açúcar, Álcool e Subprodutos, Piracicaba, v. 11, n. 14, p. 16-23, 1993.

CAVAlCANTE, F. J. A. Fósforo, do solo. Pesquisa Agropecuária Pernambucana, Recife, v. 2, n. 1, p. 7387, jun. 1978.

COLETI, J. T.; CASAGRANDE, J. C.; STUPIELlO, J. J.; RIBEIRO, L. O.; OLIVEIRA, G. R. Remoção de macronutrientes pela cana-planta e cana-soca, em argissolos, variedades RB 835486 e SP 81-3250. In: CONGRESSO NACIONAL DA STAB, 8., 2002, Pernambuco. Anais... Pernambuco: STAB, 2002. p. 316321.

EMPRESA BRASILEIRA DE PESQUISA AGROPECUÁRIA - EMBRAPA. Centro Nacional de Pesquisa de Solos (Rio de Janeiro, RJ). Sistema brasileiro de classificação de solos. 2. ed. Rio de Janeiro: Embrapa Solos, 2006, 306 p.

FERNANDES, A. C. Cálculos na agroindústria da canade-açúcar. Piracicaba: STAB - Sociedade dos Técnicos Açucareiros e Alcooleiros do Brasil, 2000, 193 p.

FERNANDES, A. M.; QUEIROZ, A. C.; LANA, R. P.; PEREIRA, J. C.; CABRAL, L. S.; VITTORI, A.; PEREIRA, E. S. Estimativas da produção de leite por vacas holandesas mestiças, segundo o sistema CNPS, em dietas contendo cana-de-açúcar com diferentes valores nutritivos. Revista Brasileira de Zootecnia, Viçosa, MG, v. 30, n. 4, p. 1350-1357, 2001.

FERREIRA, D. A.; GONÇALVES, L. C.; MOLINA, L. R.; CASTRO NETO, A. G.; TOMICH, T. R. Características de fermentação da silagem de cana-deaçúcar tratada com uréia, zeólita, inoculante bacteriano e inoculante bacteriano/enzimático. Arquivos Brasileiros de Medicina Veterinária e Zootecnia, Belo Horizonte, v. 59, n. 2, p. 423-433, 2007.

FERREIRA, D. F. SISVAR: um programa para análises e ensino de estatística. Revista Cientifica Symposium, Lavras, v. 6, n. 2, p. 36-41, 2008.

FRANZOLIN, M. H. T.; LUCCI, C. S.; FRANZOLIN, R. Efeitos de rações com níveis crescentes de canade-açúcar em substituição à silagem de milho sobre a população de protozoários ciliados no rúmen de ovinos. Revista Brasileira de Zootecnia, Viçosa, MG, v. 29, n. 5, p. 1452-1457, 2000.

FREITAS, A. W. P.; PEREIRA, J. C.; ROCHA, F. C.; COSTA, M. G.; LEONEL, F. P.; RIBEIRO, M. D. Avaliação da qualidade nutricional da silagem de canade-açúcar com aditivos microbianos e enriquecida com resíduo da colheita de soja. Revista Brasileira de Zootecnia, Viçosa, MG, v. 35, n. 1, p. 38-47, 2006 a.

FREITAS, A. W. P.; PEREIRA, J. C.; ROCHA, F. C.; DETMANN, E.; RIBEIRO, M. D.; COSTA, M. G.; LEONEL, F. P. Características da silagem de cana-deaçúcar tratada com inoculante bacteriano e hidróxido de sódio e acrescida de resíduo da colheita de soja. Revista Brasileira de Zootecnia, Viçosa, MG, v. 35, n. 1, p. 4859, 2006b. 
KORNDORFER, G. H.; ALCARDE, J. C. Acúmulo e teor de fósforo em folhas de cana-de-açúcar. Revista Brasileira de Ciência do Solo, Campinas, v. 16, n. 2, p. 217-222, 1992.

LIMA, M. L. M.; MATTOS, W. R. S. Cana-de-açúcar na alimentação de bovinos leiteiros. In: SIMPÓSIO SOBRE NUTRIÇÃO DE BOVINOS, 5., 1993, Piracicaba. Anais... Piracicaba: FEALQ, 1993. p. 77-105.

MACHADO, J. C.; OLIVEIRA, M. W.; BARBOSA, M. H. P.; MENDES, L. C.; SILVA, F. L.; ROZANE, D. E. Adubação fosfatada, produção de sacarose e qualidade do caldo da RB72-454 no ciclo de cana-planta e de primeira rebrota. In: CONGRESSO BRASILEIRO DE CIÊNCIA DO SOLO, 29., 2003, Ribeirão Preto. Anais... Ribeirão Preto: SBCS, 2003. CD-ROM.

MAGALHÃES, J. V. Absorção e translocação de nitrogênio por plantas de milho (Zea mays, L.) submetidas a periodos crescentes de omissão de fósforo na solução nutritiva. 1996. Dissertação (Mestrado em Solos e Nutrição de Plantas) - Universidade Federal de Viçosa, Viçosa, MG.

MALAVOLTA, E.; VITTI, G. C.; OLIVEIRA, S. A. Avaliação do estado nutricional das plantas. Piracicaba: Associação Brasileira para Pesquisa da Potassa e do Fosfato, 1989. $201 \mathrm{p}$.

MENDES, L. C. Eficiência nutricional de cultivares de cana-de-açúcar. Viçosa, 2006. Dissertação (Mestrado em Fitotecnia) - Universidade Federal de Viçosa, Viçosa, MG.

MENDES, L. C.; BARBOSA, M. H. P.; OLIVEIRA, M. W.; ROZANE, D. E.; MARQUES, W. P.; REBEIRO, W. R. M. Perdas de nitrogênio pela folhagem da cana durante a senescência foliar. In: ZOOTEC 2004, 14., 2004, Brasília. Anais... Brasília: ABZ, 2004. CD-ROM.

NOVAIS, R. F.; SMITH, T. J. Fósforo em solos e planta em condições tropicais. Viçosa, MG: Universidade Federal de Viçosa, 1999, 399 p.
OLIVEIRA, M. W.; FREIRE, F. M.; MACÊDO, G. A. R.; FERREIRA, J. J. Nutrição mineral e adubação da cana-de-açúcar. Informe Agropecuário, Belo Horizonte, v. 28 , n. 239, p. 30-43, 2007.

RAIJ, B. V. Fertilidade do solo e adubação. São Paulo: Ceres, 1991. $343 \mathrm{p}$.

ROSSIELLO, R. O. P. Bases fisiológicas da acumulação de nitrogênio e potássio em cana-de-açúcar (Saccharum spp., cv Na 56-79) em resposta à adubação nitrogenada em cambissolo. 1987. Dissertação (Mestrado em Solos e Nutrição de Plantas) - Escola Superior de Agricultura Luíz de Queiroz. Universidade de São Paulo, Piracicaba.

SALAS, M.; AUMONT, G.; BIESSY, G.; MAGNIE, E. Effect of variety, stage of maturity and nitrate fertilization on nutritive value of sugarcane. Animal Feed Science and Technology, Amsterdam, v. 39, n. 3, p. 265-277, 1992.

SILVA, D. J. Análise de alimentos: métodos químicos e biológicos. Viçosa: Universidade Federal de Viçosa. 1990. 165 p.

SILVA, E. A.; FERREIRA, J. J.; RUAS, J. R. M.; PAES, J. M. V.; MACEDO, G. A. R. Utilização da cana-de-açúcar na alimentação de ruminantes. Informe Agropecuário, Belo Horizonte, v. 28, n. 239, p. 102-119, 2007.

SILVA, E. T. Área foliar, crescimento e produção de sacarose por duas cultivares de cana-de-açúcar (Saccharum spp) influenciada por doses de fósforo. 2007. Dissertação (Mestrado em Agronomia) - Universidade Federal de Alagoas, Maceió.

SILVEIRA, L. C. I.; OLIVEIRA, M. W.; BARBOSA, M. H. P.; ANDRADE, M. B. M.; MENDES, L. C. Crescimento e acúmulo de sacarose por seis variedades de cana. In: CONGRESSO NACIONAL DA SOCEDADE DOS TÉCNICOS AÇÁCAREIROS E ALCOOLEIROS DO BRASIL, 8., 2002, Recife. Anais... Recife: STAB, 2002. p. 331-336. 
